\title{
The Impact of Trust in Public Institutions on Compliance With Epidemiological Measures to Slow Down the Spread of COVID-19
}

\section{Anetta Caplanova ( $\square$ anetta.caplanova@euba.sk)}

University of Economics in Bratislava

\section{Rudolf Sivak}

University of Economics in Bratislava

\section{Estera Szakadatova}

University of Economics in Bratislava

\section{Research Article}

Keywords: Institutional trust, social distancing, face covering measures, compliance, COVID-19, Slovakia

Posted Date: December 14th, 2020

DOI: https://doi.org/10.21203/rs.3.rs-115303/v1

License: (1) (i) This work is licensed under a Creative Commons Attribution 4.0 International License.

Read Full License 


\section{Abstract}

This paper investigates the causal relationship between the trust in institutions and compliance with measures introduced to slow down the spread of the novel coronavirus COVID-19 in Slovakia. We also analyse the impact of socio-economic characteristics on compliance with introduced measures. We use the data from a survey carried out by the Slovak Academy of Sciences on the representative sample of 1000 respondents. To derive the causal effect, we use a probit regression model. We find that trust in institutions helps to increase compliance with social distancing. We find that some socio-economic characteristics such as employment status, age or whether individuals feel to be in danger of COVID-19 have a positive and statistically significant effect on compliance with measures employed to slow the spread of the COVID-19 virus.

\section{Introduction}

On the $30^{\text {th }}$ January 2020, the World Health Organization declared the novel coronavirus COVID-19 outbreak as a public health emergency of international concern and in March 2020 it declared a global pandemic (WHO, 2020). At the beginning of the spread of the virus, western countries had not expected to be hit by the pandemic so hard. Having limited or no experience with large epidemiological outbreaks, many governments had failed to prepare for the rising numbers of infections and to act quickly.

So far, the COVID-19 pandemic has affected countries around the world, has tested their health care systems and capacities to deal with the increasing infection rates and had an adverse impact on their economies and social life. To slow down the spread of the virus, the WHO recommends washing hands, wearing face coverings and applying social distancing (WHO, 2020) and the focus of measures introduced by the governments is at increasing such behaviour in the population. Thus, the governments have introduced measures aimed to decrease the spread of the virus, which have been predominantly linked to social distancing measures and also to wearing face coverings. However, these measures will be effective, only if citizens comply with them. Even though the compliance with introduced measures is in the social interest and can limit health and economic costs of the pandemic, people frequently do not act accordingly. Especially in the second wave of the pandemic in the Fall of 2020, we observe that many people oppose the measures and fail to comply with them. The answer to the question why it is so is key to a better understanding, which policies can enhance the compliance with these measures and thus, their effectiveness in the future. The understanding of factors affecting the compliance of citizens with introduced measures can help governments to overcome the resistance of these population groups and limit health and economic costs of the pandemic. In that regard, it is worth distinguishing between measures, which are more difficult to be enforced and there is larger need to rely on voluntary compliance (such as social distancing measures), and the measures with which the compliance is easier to monitor and thus, to enforce (such as wearing of face coverings).

In this paper, we use the survey data collected by the Slovak Academy of Sciences in Slovakia during the first wave of the pandemic (in April 2020) to study factors affecting compliance with social distancing 
measures and with wearing face coverings. In particular, apart from socio-economic characteristics, we study whether trust in public institutions affects the compliance decisions of individuals.

The paper is structured as follows: in the next section, we provide the overview of relevant literature, next, we introduce the data, the methodology and the empirical strategy used. Then, we present the estimation results. Finally, we present conclusions and discuss the findings.

\section{Review Of Relevant Literature}

As the data related to Covid-19 pandemic becomes available for individual countries and internationally, the researchers from different academic fields study various aspects of the pandemic. Social scientists predominantly focus on its social aspects and economic and non-economic consequences. They analyse how behaviour of individuals is affected and how it affects the pandemic and how to limit the economic and social costs of the COVID-19 epidemic.

As stated above, the effort to limit the spread of the virus will be successful only if people adhere to the recommended behavioural patterns. In their study, based on the data obtained from an online survey carried out in April 2020 among the US residents Van Rooij et al. (2020) assessed factors that influence the compliance of respondents with the stay at home and social distancing measures. They conclude that people tend to comply less, when they fear the authorities. Moreover, they found that people's capacity to obey the rules, opportunity to break the rules, and self-control are positively correlated with the compliance with the introduced measures. They also found that compliance decisions significantly depend on intrinsic motivations, such as moral support and social norms.

Miguel et al. (2020) studied the effect of antisocial traits on the compliance of individuals with COVID-19 measures. On the sample of Brazilian adults, they found that antisocial traits, especially lower levels of empathy and higher levels of callousness, deceitfulness, and risk-taking are directly associated with lower compliance with containment measures. They consider these factors to provide a partial explanation, why people do not adhere to the containment measures even if the numbers of cases and deaths increase.

In their preprint study based on an online survey among Brazilian residents, Farias and Pilati (2020) find that individuals, who support right-wing parties, unemployed, young people and men have higher intentions to violate social distancing measures. They also find this to be the case for people exhibiting higher intolerance of uncertainty, people earning lower wages, or having low job stability. Social norms also play a significant role, but only when using family and friends as referents.

On the analysis of the nationally representative sample of UK residents, Kooistra et al. (2020) concluded that people's compliance with lockdown and social distancing measures depended on their capacity to comply with the rules, and on the normative obligation to obey the law, i.e. whether people morally believed that measures should be followed. Rather surprisingly they found a negative association of the compliance with whether people feared the disease, thus, people having more fear of the virus being more 
likely to break the measures. Moreover, the data show that the costs of compliance are not associated with compliance with the measures. Also, people with more negative emotions were less likely to comply with the lockdown measures. The authors point out that they did not find any conclusive evidence that stricter punishment on its own could reduce non-compliance with measures.

Almutairi et al. (2020) carried out a cross-sectional study using responses based on the survey carried out in Saudi Arabia. They found that respondents in this survey provided very high support to the containment measures (over 98 percent) with female, older, and more educated individuals respecting the containment measures more than others.

Zhi Zhao et al. (2020) analysed compliance with social distancing in association with mental health of individuals in Hong Kong. Older respondents and respondents having higher education had the tendency to comply more with social distancing measures. Also, women and economically inactive individuals reported significantly higher compliance with social distancing. Respondents with higher income had the perception of higher compliance with social distancing measures. They also looked at the impact of social distancing measures on stress, anxiety and depression among respondents. They identified that adopting more social distancing measures was significantly associated with lower stress level and lower risk of anxiety symptoms. Perceived compliance with social distancing measures and their perceived effectiveness were associated with lower stress levels and with lower risk of anxiety and depressive symptoms. On the other hand, more days stayed-at-home were associated with anxiety symptoms especially for older respondents and respondents with primary or lower education attainment.

The longitudinal study carried out using the data collected in Zurich, Switzerland, (Nivette et al., 2020) among teenagers and young adults during the first weeks of the pandemic - during the period when Switzerland was still hardly hit by its first wave. They found the non-compliance especially with hygienerelated measures to be more prevalent in males, and in individuals with higher education, of higher socioeconomic status, and of a non-migrant background. Non-compliance was higher among young adults who scored high on indicators of "antisocial potential," including low acceptance of moral rules, prepandemic legal cynicism, low shame/guilt, low self-control, engagement in delinquent behaviours, and association with delinquent peers. Young adults with low trust, including in the government's measures for fighting the virus, had also the tendency to comply less.

Zajenkowski et al. (2020) used the data obtained from a survey to examine the role of personality traits and individual perceptions of the COVID-19 pandemic situation to account for differences in compliance with the governmental restrictions in Poland. They found that the way people perceived the situation explained more variance in compliance than personality traits.

The compliance with pandemic measures has been studied also with regard to the political views of individuals. Painter and Qiu (2020) used geolocation data in the US to document that political beliefs affect the effectiveness of state-level social distancing orders. They found that residents in republican counties were less likely to comply with these orders relative to those in democratic counties. Also, using 
the debit card transaction data they found that democrats were more likely to switch to remote spending after the implementation of stay at home orders than republicans.

The trust in institutions, which is being considered relevant for compliance of individuals with pandemic measures has been studied for a long time by researchers with regard to its impact on behaviour of people in different settings. In addition, factors affecting trust in public institutions have been studied. Kampen et al. (2006) analysed the causal relationship between satisfaction and trust in public agencies in Belgium. Their main findings suggest a significant relationship between experience with public agencies impacts and the trust. They find that bad experience has a more pronounced impact on the trust in these agencies than a positive one. This conclusion indicates that to increase the trust in government, the number of unsatisfied customers with services of government agencies should be decreased.

Jimenez and lyer (2016) use the trust primacy model introduced by Holtz (2013) to study the relationship between the trust in government and tax compliance decisions. Specifically, they study whether perceived fairness of a tax system mediates the effect of trust in government tax compliance. The results point to a statistically significant relationship between trust in government and tax compliance decisions, where trust is mediated by perceived fairness.

Foster and Frieden (2017) analysed the socio-economic determinants of trust of Europeans in government. In particular, they studied the reasons for the sharp decline in confidence in public institutions after 2009, i.e. after the Financial crisis. Using the Eurobarometer survey data, they found that the decline in government trust is negatively related to economic factors, e.g. they found a significant negative relationship between the unemployment rate and the degree of trust in government. They point to the fact, that these results not only hold at the national level, but the confidence in public institutions has declined also towards the EU institutions.

In his study, Rudolph (2009) highlights that individuals support the decisions of the government, when they perceive the government as trustworthy. However, when they do not trust the government, they refuse to support the decisions the government makes.

Based on these studies we observe that trust in government and relevant government institutions affects the behaviour of citizens towards the measures introduced by the government. Also, socio-economic characteristics were confirmed to be significant with regard to the compliance with government measures. In the next sections, we will study, how these factors affected the perceptions of Slovak citizens towards compliance with COVID-19 measures.

\section{Data And Methodology}

\section{A. Data}

In our analysis, we use the data from the survey "How are you Slovakia?, April 2020" ("Ako sa máte, Slovensko?, Apríl 2020"). This survey was designed and carried out by MNFORCE Ltd., Seesame Ltd., The 
Institute for Sociology of the Slovak Academy of Sciences (SAV) and The Institute for Research in Communication of SAV. This survey was conducted during the first wave of the COVID-19 pandemic (between $21^{\text {st }}$ and $23^{\text {rd }}$ April 2020) on a sample of 1000 respondents. The sample was chosen so as it was representative for socio-demographic characteristics of the Slovak population, i.e. age, gender, district, size of the city of residence and education attainment.

The survey tracks people's perception of the COVID-19 pandemic. Particularly, it monitors for example the compliance with pandemic measures, the changes in behaviour of respondents due to COVID-19, their expectations with regard to the duration of the pandemic, etc. It also provides information on the changes in the employment status and the income of respondents. Moreover, the survey also tracks, how respondents' socialising patterns changed as a consequence of the pandemic and how the pandemic and the measures taken affected their family relationships. The survey was carried out online, thus, the sample of older respondents may not be representative of this population group, since only those, who have access to internet and are familiar with the use of internet technologies, would be included in the survey.

Table 1 provides information on respondents' socio-economic characteristics. The background characteristic analysis suggests that there were by 3 percent more women in the sample than men. Moreover, as more than half of the respondents reported to be employed or self-employed, the sample of respondents analysed is predominantly based on this population group, followed by pensioners $(25.2$ percent) and students (8.2 percent). More than one quarter of the respondents were over the age of 60 and three quarters of respondents had secondary vocational, or full secondary education. Almost half of the respondents live in smaller settlements with less than 5000 inhabitants. The characteristics of the sample of respondents as depicted in Table 1 confirm that the sample is representative of the population of the Slovak Republic.

\section{Methodology}

The methodology and empirical strategy used to estimate the causal relationship between the trust in public institutions - namely the Slovak government, Health care institutions and the Pandemic commission, which comprises of Slovak epidemiologists and health care experts - and society's compliance with the rules is based on the model specified below. The empirical data are analysed using a probit regression. In particular, we used a probit model jointly with STATA survey command to account for the survey structure of the dataset. We also consider social-economic characteristics of respondents and their significance for the compliance decision.

The dependent variables of our interest are compliance with social distancing measures and compliance with face covering requirements. The outcome variables are binary variables, taking value equal to one if a respondent reported compliance with the measures of our interest, zero otherwise.

To derive the causal effect, we use the following probit model specification: 


$$
\operatorname{Pr}\left(i_{\text {complies }}\right)=\alpha+\beta \text { Trust }_{i j}+\delta \boldsymbol{X}_{i}+\varepsilon_{i}
$$

Where the dependent variable is compliance with social distancing or face covering measures, Trust $t_{i j}$ is a binary variable indicating whether individual $i$ trusts public institution $j, X_{i}$ is a vector of socio-economic characteristics of individual $i$ and $\varepsilon_{i}$ is the error term.

The coefficients of our interest are $\beta$ which reflects causal relationship between institutional trust and compliance behaviour and reflects causal relationship between socio-economic characteristics of individuals and their compliance behaviour.

\section{Results}

In this section we present the estimation results, using the methodology outlined in the previous section. In addition, we supplement the results with an analysis of subpopulations of compliers and noncompliers with social distancing and face covering measures. We dropped the observations for individuals who were indifferent in trusting the public institutions. Thus, the number of observations is lower than the sample size, i.e. 934 observations, which we still deem sufficiently large for the robustness and representativeness of our analysis.

We predominantly focus on the impact of trust in different institutions on compliance. In the first column we present the results considering trust of respondents in health institutions. The second column considers trust in government, while the specification used in the third column considers trust in the pandemic commission. Finally, in column four we evaluate jointly the effect of trust variables on compliance with introduced measures. The significance of socio-economic characteristics is considered in each regression as well.

\section{A. Effect on compliance with social distancing measures}

Estimation results in column 1 of Table 2 suggest that trust in health institutions has a positive and statistically significant impact on compliance with social distancing measures. We find that those who trust health institutions are 59 percent more likely to follow social distancing. This estimate is significant at 1 percent level. Considering the trust estimate in the second column we find that those who trust the government are approximately 43 percent more likely to comply with social distancing measures, and this estimate is significant at 5 percent level. If we consider the individual effect of trust in the pandemic commission (column 3), the results suggest that those who trust this institution are highly likely to comply with the given measure. Particularly, those who trust the pandemic commission, are almost 86 percent more likely to practice social distancing while this estimate is statistically significant at 1 percent level of significance. Finally, if we consider the trust variables jointly, the estimates indicate that only trust in pandemic commission has a positive and statistically significant impact on compliance with social distancing measures. Individuals trusting the pandemic commission are 88 percent more likely to follow these measures and this estimate is significant at 1 percent level. Since the pandemic commission 
consists of health experts as well as health institution representatives and government officials, this might be the reason why other trust variables are not significant in this particular analysis. Thus, it may be the case that trust in pandemic commission partly captures trust in other institutions too.

In both analyses, where the trust in the permanent pandemic commission, which during the first wave of the COVID-19 pandemic, was the main expert advisory body of the government, this variable was significant at 1 percent level. Also, other trust variables were significant as explained above. Thus, this indicates that trying to enhance the compliance with social distancing measures, the government should build trust of their citizens in the government itself and in other relevant public institutions.

As for the other factors significantly affecting the compliance with social distancing measures, we evaluate the impact of other socio-economic characteristics. As can be seen in Table 2, the compliance of people, who are employed tends to be significantly larger than those, who have other employment status. The estimates suggest that employed individuals are 60 to 65 percent more likely to comply with social distancing measures than people with other employment status and this estimate is statistically significant at 1 percent level. This is an understandable finding, since in the work place the virus can spread easily and compliance with social distancing measures can contribute to decreasing its spread.

As can be seen in columns 3 and 4, the related regression analysis has shown that pensioners are also significantly more likely to comply with social distancing measures, but these estimates are statistically significant only at 5 percent level. This can be explained by older people being more vulnerable to the virus. Moreover, the estimated results suggest that those who feel in danger of COVID-19, are about 50 percent more likely to follow social distancing measures, while these estimates are significant at 5 percent level for each set of the analysis performed. This is a sign that people who feel in danger tend to comply with the rules more, which implies the importance of mass objective information about the risks of this particular disease (but also in other contexts) to make people fully aware of health consequences of non-compliance.

In our study, gender and the number of people living in a household do not statistically significantly affect the compliance of people with social distancing measures. However, it is interesting that individuals who have more mobile phones tend to statistically significantly comply less with social distancing measures. The estimates indicate that individuals who have more mobile phones are up to almost 45 percent less likely to comply with these measures. Perhaps, this variable could be used as a proxy for more extensive use of online media (e.g. social networks), including those relating to the diverging/fake news about the virus and related effects. And thus, more extensive use of online media could create confusion and consequently lower compliance with social distancing measures.

In addition to the regression analysis of the causal relationship between exogenous and dependent variables of our interest, we also looked into the proportions of compliers, who trust public institutions.

As can be seen from Table 3, those who comply with social distancing measures, are more likely to trust public institutions. The results suggest that almost 80 percent of compliers with social distancing 
measures trust the health institutions. We can see similar pattern when we consider the trust in pandemic commission - in this case 71.5 of compliers trust the pandemic commission.

If we consider the subpopulation of non-compliers, we find that those who do not follow the social distancing measures are less likely to trust the government. However, quite interestingly, if we consider the subpopulation of non-compliers with social distancing measures, we find that approximately 71 percent of non-compliers trust the pandemic commission, but they do not follow their recommendations on social distancing.

\section{B. Effect on face covering compliance measures}

In Table 4 we present the results of the analysis of compliance with face covering measures, i.e. with wearing face masks.

In contrast to the results presented in the previous section, the estimated relationship between trust in public institutions and compliance with face covering measures is insignificant. This holds when we consider the effect of trust variables independently of each other, as well as when we analyse their joint impact on compliance behaviour. This may be because wearing face coverings was compulsory at the time, when this survey was carried out.

However, we find that some individual characteristics have positive and significant impact on compliance with given measure. Even though we find no statistically significant relationship between being a pensioner and compliance, the estimated results presented in Table 4 suggest that individuals older than 50 years 55 to 57.5 percent more likely to comply with face covering measures. These results are highly statistically significant, i.e. at 1 percent level. This can be due to older people being more vulnerable to the virus and be willing to protect themselves using face covering. However, given that age did not come out as statistically significant, when social distancing measures were considered, we might speculate that this may perhaps be due to lower intensity of social contacts of older people, who may not consider it important for them to comply with social distancing measures. Estimates in Table 4 also suggest that those who fell in danger of COVID-19 are more likely to wear face coverings. In particular, they are approximately 25 to 26 percent more likely to comply with face covering measures. Finally, we find that the number of people in the household (i.e. the size of the household) has a positive statistical impact on compliance with face covering measures. The estimates for all four specifications are significant at 5 percent level. Also, people, who feel in danger of COVID-19 tend to statistically significantly more comply with face covering measures but this is significant at 5, 10 percent significance level only. However, in difference to the analysis in the previous section, the estimate of the number of mobile phones has not a statistically significant impact on the decision to comply with wearing face coverings.

We also looked at the subpopulations of (non)compliers with face covering measures and their trust in public institutions. The results are summarized in Table 5. By looking at the percentages we see that there does not emerge a clear pattern for trust in these institutions among compliers that would distinguish them from non-compliers. 
The results suggest that majority of compliers as well as non-compliers with face covering measures trust the health institutions and the pandemic commission.

It is striking that a larger share of non-compliers trusts the health institutions than it is the case in the subpopulation of compliers. This is surprising since health institutions and health experts were highlighting the significance of face covering wearing as an important instrument to slow the spread of the virus from the onset of the pandemic. Thus, even though these people trust these institutions, they do not comply with their face wearing measures.

To evaluate, whether the independent variables reliably predict the dependent variables of our interest, i.e. compliance with social distancing and compliance with face covering measures, we use F-statistics. Thus, we test the significance and joint significance for the specifications used to estimate the causal effect. We find that the reported $p$-values are smaller than the 5 percent critical value (see Appendix, Table A1), therefore we reject the null hypothesis and conclude that the independent variables are significant and reliably predict the depend variables. Therefore, we conclude that the estimated results presented above are robust.

\section{Conclusions And Discussion}

The estimation results presented in the sections above indicate that trust in public institutions is a significant factor when considering the impact of voluntary measures directed at individual citizens. As we have shown this is relevant for increasing compliance with epidemiological measures implemented to address the COVID-19 pandemic. Using the survey data from Slovakia we find that trust in institutions such as pandemic committee, health institutions and government has positive significant impact on compliance with social distancing measures. Even though, we find no statistically significant effect of trust on compliance with face covering measures, as mentioned, this can be explained by the compulsory nature of wearing face masks at the time, when the survey was implemented.

This suggests that to increase voluntary compliance with COVID-19 measures, public health campaigns should implement strategies that foster trust in government and other relevant public authorities involved in the decision making and implementing measures to slow the spread of the COVID-19 virus.

We also find that certain socio-economic characteristics have a positive significant impact on compliance with social distancing and face covering measures. The results suggest that those who are employed are significantly more likely to follow social distancing measures. Furthermore, the estimates indicate that those who feel in danger of COVID-19 as well as pensioners are more likely to socially distance from other people. When considering compliance with face covering measures, we find that individuals above the age of 50 are more likely to comply with them. These results suggest that those who belong to the risky groups of population are aware of the risks the virus poses on their health and adjust their behaviour accordingly. Also, the use of well targeted nudging at those groups that tend to comply less, should contribute to increased compliance with epidemiological measures. 
The access to online networks has also been shown to play a role in compliance with social distancing measures. We find that people having more mobile phones are less likely to comply with social distancing measures. Using the ownership of mobile phones as a proxy for access or extend of use of online media, it indicates that larger use of these media can perhaps generate confusion over the employed measures and thus, reduce compliance. Given the rise of fake news and information regarding the coronavirus COVID-19, especially on social media platforms, it could indicate that larger use of online media fosters access to fake information. Therefore, this could explain why those having more mobile devices would be less likely to comply with social distancing measures.

We believe that our research on the impact of trust in public institutions on compliance with epidemiological measures provides further support for the role of trust in public institutions in democratic societies. Thus, not only in challenging and uncertain times such as the COVID-19 pandemic it is important that governments and government bodies build and sustain the trust of their citizens.

\section{Declarations}

\section{Note}

This paper was prepared with the support of the projects of the Scientific Grant Agency of the Ministry of Education of the Slovak Republic (VEGA 1/0239/19) Implications of Behavioral Economics for Streamlining the Functioning of Current Economies and of the Slovak Research and Development Agency (APVV 18-0435) Behavioral Interventions in Local Government: Increasing the Efficiency of Local Public Policies.

Author contributions: A.C. and E.SZ. wrote the main manuscript text and R.S. prepared the conceptualization of the paper. All authors reviewed the manuscript.

The authors do not have any competing interests related to the content presented in this article.

\section{References}

Almutairi, A. F., BaniMustafa, A. A., Alessa, Y. M., Almutairi, S. B., \& Almaleh, Y. (2020). Public trust and compliance with the precautionary measures against COVID-19 employed by authorities in Saudi Arabia. Risk Management and Healthcare Policy, 13, 753.

Farias, J. E. M., \& Pilati, R. (2020). Violating social distancing amid COVID-19 pandemic: psychological factors to improve compliance.

Foster, Ch., \& Frieden, J. (2017). Crisis of trust: Socio-economic determinants of Europeans' confidence in governments. European Union Politics 18(4), 511-535.

Holtz, B. (2013). Trust primacy: A model of the reciprocal relations between trust and perceived justice. Journal of Management, 39(7), 1891-1923. 
Jimenez, P., \& lyer, G. S. (2016). Tax compliance in a social setting: The influence of social norms, trust in government, and perceived fairness on taxpayer compliance. Advances in accounting, 34, 17-26.

Kampen, J. K., De Walle, S. V., \& Bouckaert, G. (2006). Assessing the relation between satisfaction with public service delivery and trust in Government. The impact of the predisposition of citizens toward Government on evaluations of its performance. Public Performance \& Management Review, 29(4), 387404.

Kooistra, E. B., et al. (2020). Mitigating covid-19 in a nationally representative UK sample: Personal abilities and obligation to obey the law shape compliance with mitigation measures (Amsterdam Law School Research Paper No. 2020-19).

Miguel, F. K., Machado, G. M., Pianowski, G., \& de Francisco Carvalho, L. (2020). Compliance with containment measures to the COVID-19 pandemic over time: Do antisocial traits matter?. Personality and individual differences, 168, 110346.

MNFORCE, s.r.o. Seesame, s.r.o. Sociologický ústav SAV. Ústav výskumu sociálnej komunikácie SAV. Ako sa máte, Slovensko?, April 2020. [dátový súbor]. Slovenský archív sociálnych dát, 2020. SASD2020002. Verzia 1.0. DOI: https://doi.org/10.34877/sasd-2020002.

Nivette, A., et al. (2020). Non-compliance with COVID-19-related public health measures among young adults in Switzerland: Insights from a longitudinal cohort study. Social Science \& Medicine, 268, 113370.

Rudolph, T. J. (2009). Political trust, ideology, and public support for tax cuts. Public Opinion Quarterly, 73(1), 144-158.

Van Rooij, B., et al. (2020). Compliance with covid-19 mitigation measures in the United States. Available at SSRN 3582626.

World Health Organization. (2020). Timeline: The WHO's COVID-19 response. Available at: https://www.who.int/emergencies/diseases/novel-coronavirus-2019/interactive-timeline\#! [Accessed on $11^{\text {th }}$ Nov 2020].

World Health Organization. (2020). Coronavirus disease (COVID-19) advice for the public. Available at: https://www.who.int/emergencies/diseases/novel-coronavirus-2019/advice-for-public [Accessed on $11^{\text {th }}$ Nov 2020].

Zajenkowski, M., Jonason, P. K., Leniarska, M., \& Kozakiewicz, Z. (2020). Who complies with the restrictions to reduce the spread of COVID-19?: personality and perceptions of the COVID-19 situation. Personality and Individual Differences, 166, 110199.

Zhao, S. Z., Wong, J. Y. H., Wu, Y., Choi, E. P. H., Wang, M. P., \& Lam, T. H. (2020). Social distancing compliance under Covid-19 pandemic and mental health impacts: A population-based 
study. International Journal of Environmental Research and Public Health, 17(18), 6692.

\section{Tables}

Table 1 - Sample characteristics of survey respondents. 


\begin{tabular}{|ll|}
\hline & Mean \\
\hline Gender & \\
\hline Female & $51.5 \%$ \\
\hline Male & $48.5 \%$ \\
\hline Age & \\
\hline $18-29$ years & $18.3 \%$ \\
\hline $30-39$ years & $20.4 \%$ \\
\hline $40-49$ years & $19 \%$ \\
\hline $50-59$ years & $15.8 \%$ \\
\hline More than 60 years & $26.5 \%$ \\
\hline Education & \\
\hline Elementary & $7.1 \%$ \\
\hline Non-diploma vocational & $39.5 \%$ \\
\hline High school diploma & $36.8 \%$ \\
\hline University degree & $16.6 \%$ \\
\hline Employment status & $25.1 \%$ \\
\hline Employed or Self-employed & $52.7 \%$ \\
\hline Unemployed & $5.9 \%$ \\
\hline Student & $8.2 \%$ \\
\hline Pensioner & $25.2 \%$ \\
\hline Other & $8 \%$ \\
\hline Size of the city & $45.7 \%$ \\
\hline Less than 4999 & \\
\hline $5000-19999$ & \\
\hline $20000-99999$ & \\
\hline More than 100000 & \\
\hline Number of people in household & 2.94 \\
\hline
\end{tabular}

Table 2 - Estimation results. 
Dependent variable is compliance with social distancing measures. 


\begin{tabular}{|c|c|c|c|c|}
\hline & $(1)$ & (2) & (3) & (4) \\
\hline VARIABLES & Col 1 & Col 2 & Col 3 & Col 4 \\
\hline \multirow[t]{2}{*}{ Age $>=50$} & -0.0583 & -0.0882 & -0.188 & -0.179 \\
\hline & $(0.235)$ & $(0.236)$ & $(0.234)$ & $(0.226)$ \\
\hline \multirow[t]{2}{*}{ Gender } & -0.104 & -0.132 & -0.110 & -0.0923 \\
\hline & $(0.200)$ & $(0.195)$ & $(0.204)$ & $(0.208)$ \\
\hline \multirow[t]{2}{*}{ Population of city } & 0.0155 & 0.0111 & 0.0107 & 0.0159 \\
\hline & $(0.0805)$ & $(0.0801)$ & $(0.0847)$ & $(0.0854)$ \\
\hline \multirow[t]{2}{*}{ Employed } & $0.611 * * *$ & $0.602^{* \star *}$ & $0.655^{\star \star \star}$ & $0.656^{* * *}$ \\
\hline & $(0.231)$ & $(0.220)$ & $(0.237)$ & $(0.237)$ \\
\hline \multirow[t]{2}{*}{ Number of people in household } & 0.0334 & 0.0303 & 0.0230 & 0.0237 \\
\hline & $(0.0584)$ & $(0.0584)$ & $(0.0645)$ & $(0.0639)$ \\
\hline \multirow[t]{2}{*}{ Feeling in danger of COVID-19 } & $0.510 * *$ & $0.477^{* \star}$ & $0.489 * *$ & $0.502^{\star *}$ \\
\hline & $(0.199)$ & $(0.193)$ & $(0.204)$ & $(0.209)$ \\
\hline \multirow[t]{2}{*}{ Pensioner } & 0.480 & 0.478 & $0.666^{\star *}$ & $0.669 * *$ \\
\hline & $(0.308)$ & $(0.305)$ & $(0.293)$ & $(0.261)$ \\
\hline \multirow[t]{2}{*}{ Student } & -0.0745 & -0.0342 & -0.0421 & -0.0602 \\
\hline & $(0.330)$ & $(0.328)$ & $(0.332)$ & $(0.331)$ \\
\hline \multirow[t]{2}{*}{ Number of mobile phones } & $-0.436 * \star$ & $-0.414^{\star \star}$ & $-0.437 \star \star$ & $-0.449 * *$ \\
\hline & $(0.174)$ & $(0.171)$ & $(0.173)$ & $(0.175)$ \\
\hline \multirow[t]{2}{*}{ Trust in health institutions } & $0.590 * \star \star$ & & & 0.266 \\
\hline & $(0.203)$ & & & $(0.224)$ \\
\hline \multirow[t]{2}{*}{ Trust in government } & & $0.432^{\star \star}$ & & -0.191 \\
\hline & & $(0.192)$ & & $(0.245)$ \\
\hline \multirow[t]{2}{*}{ Trust in pandemic committee } & & & $0.859 * \star \star$ & $0.879 * * *$ \\
\hline & & & $(0.205)$ & $(0.290)$ \\
\hline \multirow[t]{2}{*}{ Constant } & $1.427^{\star \star \star}$ & $1.671^{\star \star *}$ & $1.445^{\star \star \star}$ & $1.322^{\star \star \star}$ \\
\hline & $(0.426)$ & $(0.398)$ & $(0.429)$ & $(0.461)$ \\
\hline
\end{tabular}


Standard errors in parentheses.

$\star, * \star, * \star \star$ significant at 10,5 and 1 percent level

Table 3 - Analysis of trust considering the subpopulation of compliers and non-compliers with social distancing measures.

\begin{tabular}{|llll|}
\hline & & Sample subpopulations \\
& $\begin{array}{l}\text { Compliers with social } \\
\text { distancing measures }\end{array}$ & $\begin{array}{l}\text { Non-compliers with social } \\
\text { distancing measures }\end{array}$ \\
\hline $\begin{array}{l}\text { Trust in health } \\
\text { institutions }\end{array}$ & Yes & 79.78 & 54.17 \\
\cline { 2 - 4 } Trust in government & No & 20.22 & 45.83 \\
\cline { 2 - 4 } & Nes & 57.58 & 33.33 \\
\hline $\begin{array}{l}\text { Trust in pandemic } \\
\text { commission }\end{array}$ & Yes & 71.43 & 66.67 \\
\cline { 2 - 4 } & No & 28.57 & 70.83 \\
\hline
\end{tabular}

\section{Table 4 - Estimation results.}

Dependent variable is compliance with face covering measures. 


\begin{tabular}{|c|c|c|c|c|}
\hline & (1) & (2) & (3) & (4) \\
\hline VARIABLES & Col 1 & Col 2 & Col 3 & Col 4 \\
\hline \multirow[t]{2}{*}{ Age $>=50$} & $0.561 * \star \star$ & $0.555^{\star \star \star}$ & $0.551 * \star \star$ & $0.575^{\star \star \star}$ \\
\hline & $(0.176)$ & $(0.178)$ & $(0.176)$ & $(0.178)$ \\
\hline \multirow[t]{2}{*}{ Gender } & -0.0353 & -0.0214 & -0.0215 & -0.0435 \\
\hline & $(0.134)$ & $(0.133)$ & $(0.133)$ & $(0.134)$ \\
\hline \multirow[t]{2}{*}{ Population of city } & 0.0695 & 0.0688 & 0.0694 & 0.0686 \\
\hline & $(0.0617)$ & $(0.0611)$ & $(0.0614)$ & $(0.0616)$ \\
\hline \multirow[t]{2}{*}{ Employed } & -0.00215 & 0.00966 & 0.00507 & -0.00175 \\
\hline & $(0.133)$ & $(0.133)$ & $(0.132)$ & $(0.133)$ \\
\hline \multirow[t]{2}{*}{ Number of people in household } & $0.110 * \star$ & $0.111^{\star \star}$ & 0.112 ** & $0.112^{\star \star}$ \\
\hline & $(0.0471)$ & $(0.0466)$ & $(0.0462)$ & $(0.0468)$ \\
\hline \multirow[t]{2}{*}{ Feeling in danger of COVID-19 } & $0.251^{*}$ & $0.260 * \star$ & $0.263^{\star \star}$ & $0.248^{*}$ \\
\hline & $(0.132)$ & $(0.131)$ & $(0.131)$ & $(0.132)$ \\
\hline \multirow[t]{2}{*}{ Pensioner } & -0.132 & -0.119 & -0.124 & -0.138 \\
\hline & $(0.193)$ & $(0.194)$ & $(0.193)$ & $(0.196)$ \\
\hline \multirow[t]{2}{*}{ Student } & 0.340 & 0.318 & 0.318 & 0.349 \\
\hline & $(0.252)$ & $(0.251)$ & $(0.251)$ & $(0.253)$ \\
\hline \multirow[t]{2}{*}{ Number of mobile phones } & 0.137 & 0.126 & 0.129 & 0.135 \\
\hline & $(0.146)$ & $(0.145)$ & $(0.146)$ & $(0.147)$ \\
\hline \multirow[t]{2}{*}{ Trust in health institutions } & -0.237 & & & -0.285 \\
\hline & $(0.176)$ & & & $(0.190)$ \\
\hline \multirow[t]{2}{*}{ Trust in government } & & 0.0924 & & 0.200 \\
\hline & & $(0.130)$ & & $(0.153)$ \\
\hline \multirow[t]{2}{*}{ Trust in pandemic committee } & & & -0.0429 & -0.0715 \\
\hline & & & $(0.140)$ & $(0.184)$ \\
\hline \multirow[t]{2}{*}{ Constant } & $0.776^{\star \star}$ & 0.524 & $0.603^{*}$ & $0.755^{\star \star}$ \\
\hline & $(0.342)$ & $(0.321)$ & $(0.318)$ & $(0.349)$ \\
\hline
\end{tabular}


Standard errors in parentheses

$\star, \star \star, \star * \star$ significant at 10,5 and 1 percent level

Table 5 - Analysis of trust considering the subpopulation of compliers and non-compliers with face covering measures.

\begin{tabular}{|llll|}
\hline & & \multicolumn{2}{l|}{$\begin{array}{l}\text { Sample subpopulations } \\
\text { measures }\end{array}$} \\
\hline $\begin{array}{l}\text { Trust in health } \\
\text { institutions }\end{array}$ & Yes & 78.67 & $\begin{array}{l}\text { Non-compliers with face covering } \\
\text { measures }\end{array}$ \\
\cline { 2 - 4 } Trust in government & No & 21.33 & 85.48 \\
\hline Yes & 57.22 & 14.52 \\
\hline $\begin{array}{l}\text { Trust in pandemic } \\
\text { commission }\end{array}$ & No & 42.78 & 53.23 \\
\hline & Yes & 70.3 & 46.77 \\
\hline
\end{tabular}

